\title{
PICTORIAL COGNITIVE TASK RESOLUTION AND EXPIRED MINUTE VENTILATION, OXYGEN CONSUMPTION, CARBON DIOXIDE PRODUCTION AND HEART RATE
}

\author{
Josef Petrek \\ Department of Physiology, Faculty of Medicine and Dentistry, Palacky University, Olomouc, Czech Republic \\ e-mail:fesoj@tunw.upol.cz
}

Received: June 7, 2008; Accepted: November 10, 2008

Key words: Cognitive task/Respiratory gases/Heart rate/Personality traits

Aims: To assess the impact of cognitive task solving on respiratory and cardiovascular parameters.

Methods: The ML870B80 Exercise Physiology System was used to record concurrently with EEG, the cardiorespiratory and metabolic functions of subjects during cognitive activity. The Expired Minute Ventilation $\left(\mathrm{V}_{\mathrm{E}}\right)$, Oxygen Consumption $\left(\mathrm{V}_{\mathrm{O} 2}\right)$, Carbon Dioxide Production $\left(\mathrm{V}_{\mathrm{CO}_{2}}\right)$ and Average Heart Rate $(\mathrm{BPM})$ were ascertained for four periods: (1) rest or starting period, (2) reference period, (3) cognitive task solving period and (4) recovery period. Each period was defined by the type of presented visual stimuli and by the prearranged cognitive activity related to visual stimuli. The personality traits of participants were also determined.

Results: The momentary functional state of subject's brain (i.e. the period of the experiment) determined the average values of all measured parameters. During the cognitive task solving period the average $\mathrm{V}_{\mathrm{E}}, \mathrm{V}_{\mathrm{O} 2}$ and $\mathrm{V}_{\mathrm{CO} 2}$ reached the lowest values while the HR behaved reversely - it was the highest in the cognitive task solving period. Further, the average $\mathrm{V}_{\mathrm{E}}, \mathrm{V}_{\mathrm{CO}}$ and $\mathrm{HR}$ values but not $\mathrm{V}_{\mathrm{O} 2}$ value differed significantly from average values for the same variable measured in the rest period.

Conclusion: The changes in respiratory variables during the cognitive task solving period predicate the whole-body metabolic rate rather than the energy metabolism of the brain alone. However, the heart rate related to some personality traits of the subject has a tighter relation to brain's energy metabolic rate during the cognitive task solving - it affects the oxygen supply of the brain.

\section{INTRODUCTION}

The brain makes an ongoing energy demand. The mean level of energy required by the brain is very high under resting conditions and it increases markedly during exercise. According to Guyton and Hall ${ }^{9}$, the brain metabolism per unit mass of tissue is about 7.5 times the average metabolism in non-nervous tissues. This means that the brain, like the other organs in the human body, needs more glucose, oxygen and other essentials under demanding conditions. The energy requirements of different areas of the brain also fluctuate over time and the delivery of oxygen and glucose change accordingly. It should be emphasized here that experimental descriptions of the coupling between demand and supply in laboratory animals was provided by Roy and Sherrington ${ }^{19}$ over a century ago. According to them, "the brain possesses an intrinsic mechanism by which its vascular supply can be varied locally in correspondence with local variations of functional activity“.

A precise quantitative assessment of the coupling between neural activity and changes in regional blood flow and/or cerebral metabolic rate of oxygen consumption or evaluation of the dynamics of other metabolic intermediates were only possible after the introduction of modern non-invasive functional brain imaging techniques*. These new imaging techniques gave researchers interested in the function of the brain a suitable tool enabling them to examine the neurobiological correlates of human behaviours. This is exemplified by the increasing number of papers published in the past several years ${ }^{\text {see e.g. } 6-8, ~ 10, ~ 14, ~ 15, ~ 20-23 . ~}$

Much of this work demonstrated that information processing in the human brain involves a concurrent activity of multiple spatially distributed cortical regions that participate in various information processing operations. They also showed that changes in the cellular activity of the brain are invariably accompanied by metabolic changes, especially changes in local blood flow, in oxygen

* Signals detected with functional brain imaging techniques (see Magistretti and Pellerin ${ }^{13}$ ) are based on the coupling between neuronal activity and energy metabolism. Positron emission tomography signals detect blood flow, oxygen consumption and glucose utilization associated with neuronal activity. The degree of blood oxygenation is thought to contribute to the signal detected with functional magnetic resonance imaging, whereas magnetic resonance spectroscopy identifies the spatiotemporal pattern of activitydependent appearance of metabolic intermediates, such as glucose or lactate. Despite the technological sophistication of these brain imaging techniques, the precise mechanism and cell types involved in coupling and in generating metabolic signals are still debated. 
Table 1. Correlation coefficients describing the relationship between the FPI score of twelve personality traits and the average values of $\mathrm{V}_{\mathrm{E}}, \mathrm{HR}, \mathrm{V}_{\mathrm{O} 2}$ and $\mathrm{V}_{\mathrm{CO} 2}$ calculated in different periods of the experiment.

\begin{tabular}{|c|c|c|c|c|c|c|c|c|c|c|c|c|}
\hline \multirow[t]{2}{*}{ Variable } & \multicolumn{12}{|c|}{$\begin{array}{l}\text { Correlations: FPI vs. VE } \\
\text { Bold numbers on a grey background - correlations are significant at } p<.05 \\
N=13\end{array}$} \\
\hline & I 1 & PI 2 & FPI 3 & FPI 4 & FPI 5 & FPI 6 & FPI 7 & FPI 8 & FPI 9 & $E$ & $\mathrm{~N}$ & $\mathrm{M}$ \\
\hline $1 \mathrm{VE}$ & & & & & $-0,81$ & $-0,49$ & 0,04 & 0,72 & & & 0,51 & 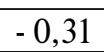 \\
\hline $2 \mathrm{VE}$ & & & & 8 & 0,50 & 0,44 & $-0,01$ & $-0,21$ & 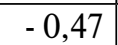 & & $-0,58$ & 0,09 \\
\hline $3 \mathrm{VE}$ & & & & & $-0,64$ & 0,46 & $-0,02$ & $\overline{0}$ & & & 0,49 & 0,14 \\
\hline $4 \mathrm{VE}$ & & & & & $-0,61$ & $-0,51$ & $-0,01$ & 0,65 & 0,24 & & 0,29 & $-0,07$ \\
\hline $5 \mathrm{VE}$ & 0 , & $-0,01$ & 0 & 0,05 & $-0,71$ & $-0,48$ & 0,02 & 0,66 & 0,29 & -0 & 0,42 & $-0,16$ \\
\hline $6 \mathrm{VE}$ & 0,18 & 0,14 & 0,62 & 0,17 & $-0,80$ & $-0,56$ & $-0,14$ & 0,62 & 0,22 & $-0,69$ & 0,42 & $-0,21$ \\
\hline
\end{tabular}

\begin{tabular}{|c|r|r|r|r|r|r|r|r|r|r|r|r|}
\hline \multirow{2}{*}{ Variable } & \multicolumn{10}{c|}{ Correlations: FPI vs. HR } \\
& \multicolumn{10}{|c|}{ Bold numbers on a grey background - correlations are significant at $\mathrm{p}<.05$} \\
\cline { 2 - 14 } & FPI 1 & FPI 2 & \multicolumn{1}{|c|}{ FPI 3 } & \multicolumn{1}{|c|}{ FPI 4 } & FPI 5 & FPI 6 & FPI 7 & FPI 8 & FPI 9 & \multicolumn{1}{c|}{ E } & \multicolumn{1}{c|}{ N } & \multicolumn{1}{c|}{ M } \\
\hline 1HR & 0,18 & $-0,42$ & $-0,15$ & 0,04 & 0,03 & $-0,15$ & $-0,19$ & 0,38 & 0,29 & $-0,23$ & 0,00 & 0,09 \\
\hline 2HR & $\mathbf{0 , 6 7}$ & $-0,52$ & $-0,19$ & $-0,24$ & $-0,52$ & $-0,23$ & 0,10 & $\mathbf{0 , 7 6}$ & 0,10 & $-\mathbf{0 , 6 2}$ & $-0,18$ & $-0,49$ \\
\hline 3HR & $\mathbf{0 , 6 5}$ & $-0,20$ & 0,17 & $-0,03$ & $-0,55$ & $-0,42$ & 0,08 & $\mathbf{0 , 6 1}$ & 0,06 & $-0,53$ & 0,37 & $-0,46$ \\
\hline 4HR & 0,46 & $-0,49$ & $-0,08$ & 0,13 & $-0,13$ & $-0,43$ & 0,07 & 0,46 & 0,14 & $-0,31$ & 0,02 & $-0,07$ \\
\hline 5HR & 0,33 & $-0,43$ & $-0,04$ & 0,10 & $-0,16$ & $-0,51$ & $-0,15$ & 0,38 & 0,25 & $-0,33$ & 0,00 & 0,10 \\
\hline 6HR & 0,24 & $-0,35$ & $-0,06$ & 0,15 & $-0,09$ & $-0,51$ & $-0,27$ & 0,27 & 0,26 & $-0,21$ & $-0,03$ & 0,19 \\
\hline
\end{tabular}

\begin{tabular}{|c|c|c|c|c|c|c|c|c|c|c|c|c|}
\hline \multirow[t]{2}{*}{ Variable } & \multicolumn{12}{|c|}{$\begin{array}{l}\text { Correlations: FPI vs. O2 } \\
\text { Bold numbers on a grey background - correlations are significant at } \mathrm{p}<.05 \\
\mathrm{~N}=13\end{array}$} \\
\hline & II 1 & गI 2 & FPI 3 & FPI 4 & FPI 5 & FPI 6 & FPI 7 & FPI 8 & FPI 9 & $E$ & $\mathrm{~N}$ & $\bar{M}$ \\
\hline 102 & & & & & $-0,67$ & $-0,42$ & & 0,61 & & & 0,55 & 0 \\
\hline 2 & & 50 & & & 0,42 & 0,41 & 0 , & -0 & 7 & & \begin{tabular}{|c|}
$-0,49$ \\
\end{tabular} & \\
\hline 3 & & & & & 0,65 & $-0,46$ & $-0,01$ & 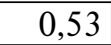 & 0,18 & 7 & 0 & 0,07 \\
\hline $4 \mathrm{O} 2$ & & 05 & & & $-0,72$ & $-0,54$ & 0,04 & 0,69 & 0, & 0,58 & 0,37 & $-0,0$ \\
\hline $5 \mathrm{O} 2$ & & $-0,05$ & 0,51 & 0,0 & $-0,69$ & $-0,44$ & 0,08 & 0,64 & 0 , & 1 & 0,35 & $-0,03$ \\
\hline $6 \mathrm{O} 2$ & 0,24 & 0,09 & 0,61 & 0,11 & $-0,72$ & $\begin{array}{l}-0,46 \\
\end{array}$ & 0,04 & 0,57 & 0,30 & $-0,53$ & 0,42 & $\begin{array}{l}-0,04 \\
\end{array}$ \\
\hline
\end{tabular}

\begin{tabular}{|c|c|c|c|c|c|c|c|c|c|c|c|c|}
\hline \multirow[t]{2}{*}{ Variable } & \multicolumn{12}{|c|}{$\begin{array}{l}\text { Correlations: FPI vs. CO2 } \\
\text { Bold numbers on a grey background - correlations are significant at } \mathrm{p}<.05 \\
\mathrm{~N}=13\end{array}$} \\
\hline & I 1 & 2 & FPI 3 & FPI 4 & FPI 5 & FPI 6 & FPI 7 & FPI 8 & FPI 9 & E & $\mathrm{N}$ & M \\
\hline $1 \mathrm{CO} 2$ & & & & & $-0,78$ & 0 & & 3 & & & 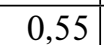 & \\
\hline $2 \mathrm{CC}$ & & & & -1 & 0,53 & & & 0,21 & 3 & & 0 & 22 \\
\hline $3 \mathrm{CC}$ & & & & & 0,60 & 4 & & 0,0 & 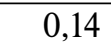 & & 1 & 3 \\
\hline $4 \mathrm{CO}$ & & 5 & 3 & 0 & $-0,59$ & \begin{tabular}{|c|}
$-0,50$ \\
\end{tabular} & 8 & 0,74 & 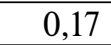 & $\mathbf{0}$, & 0,29 & $\begin{array}{l}-0,14 \\
\end{array}$ \\
\hline $5 \mathrm{CO} 2$ & & $-0,05$ & 0 & & $-0,72$ & $-0,50$ & 8 & 0,74 & 0,27 & -0 & 0 & $-0,21$ \\
\hline $6 \mathrm{CO} 2$ & 0,18 & 0,06 & 0,61 & 0,23 & $-0,78$ & 0,58 & 0,00 & 0,70 & 0,21 & $-0,63$ & 0,46 & $-0,22$ \\
\hline
\end{tabular}

FPI - Freiburg Personality Inventory, FPI1 - nervousness, FPI2 - spontaneous aggressiveness, FPI3 - depression, FPI4 - irritability, FPI5 - sociability, FPI6 - mildness, FPI7 - reactive aggressiveness, FPI8 - moderation (frustration), FPI9 - openness, E - extraversion, N - emotional lability, M - masculinity. For the other see the text to Fig. 1.

consumption and in glucose utilization. In brief, these new findings extended and specified our knowledge of the relationship between neuronal activity and energy metabolism in brain tissue, which is essential to the understanding of how the brain functions.

The new techniques of functional brain imaging play a crucial role in the study of cognitive activity of the brain. Appropriate combinations of the experimental strategies of cognitive psychology with various imaging techniques actually examine how the brain function supports mental activities. However, they have a tiny drawback. They are intended only for researchers who are not suffering from lack of funds. Namely, this is not our case. Therefore, we decided to supplement our record of an ongoing EEG and event-related brain potentials to visual stimuli with a concurrent registration the Expired Minute Ventilation, Oxygen Consumption, Carbon Dioxide Production and Finger Pulse. We did it with the aim to assess the impact, 

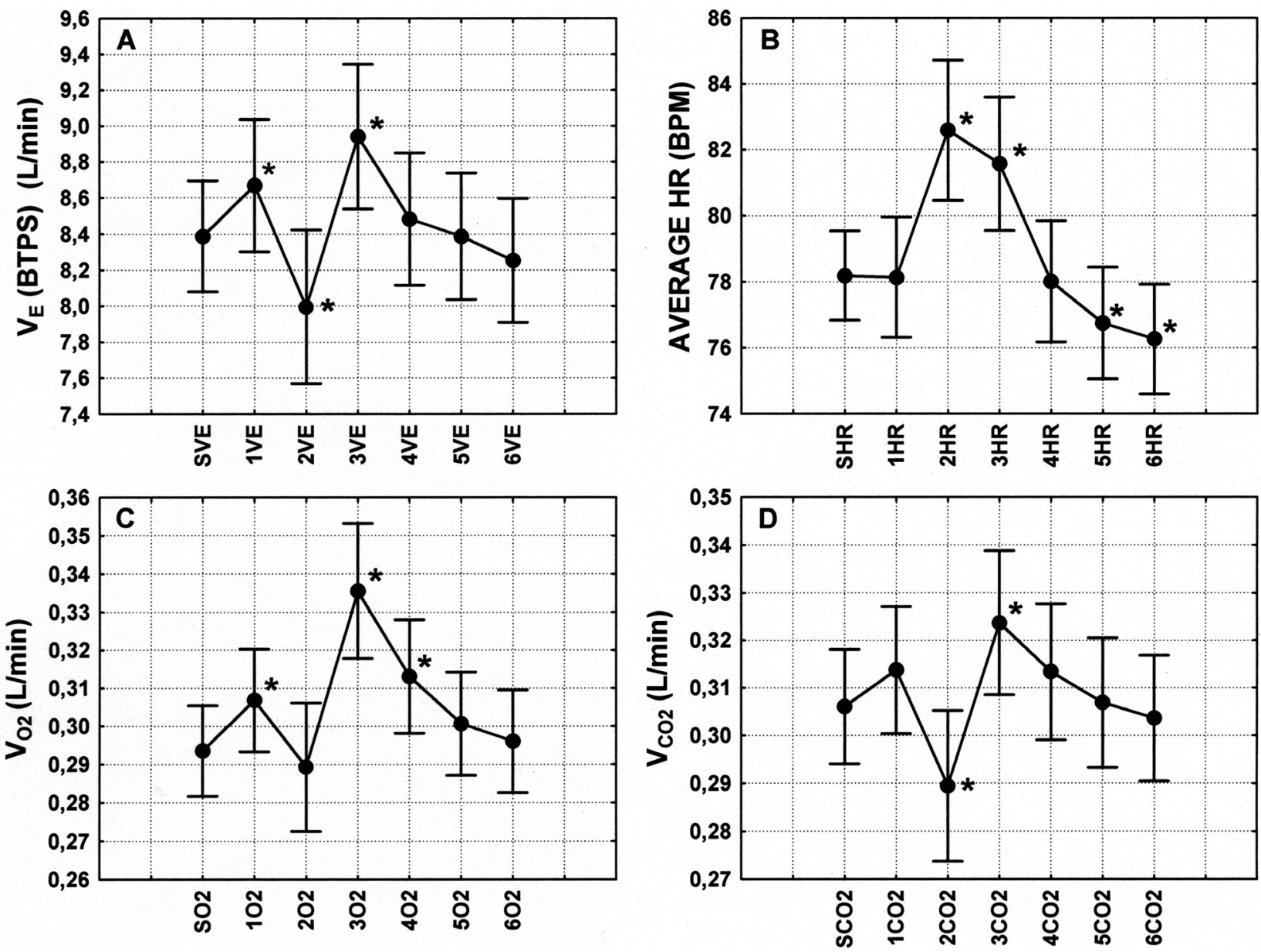

Abscissa: Average values of parameters $\mathrm{V}_{\mathrm{E}}, \mathrm{HR}, \mathrm{V}_{\mathrm{O} 2}$ and $\mathrm{V}_{\mathrm{CO} 2}$ in the starting period ( $\mathrm{S}$ ), in the reference period (1), during the cognitive task solving (2) and in the first (3), second (4), third (5) and fourth (6) 30-second intervals of the recovery period. Black circles - average values, Vertical bars - 0.95 per cent confidence intervals, Asterisk - the average value differs $(\mathrm{p}<.05)$ from the average value calculated in the starting period.

Fig. 1. Dynamics of Expired Minute Ventilation $\left(\mathrm{V}_{\mathrm{E}}\right)$, Heart Rate $(\mathrm{HR})$, Oxygen Consumption $\left(\mathrm{V}_{\mathrm{O} 2}\right)$ and Carbon Dioxide Production $\left(\mathrm{V}_{\mathrm{CO} 2}\right)$ in the course of the experiment.

whatsoever it will be, of different cognitive activities on the basic respiratory and cardiovascular parameters. The obtained results are summarized in the present paper.

\section{METHODS}

The fifteen right-handed female students from the Medical Faculty of Palacký University in Olomouc participated in the experiment. Records of only 13 were analysed - one female stopped the experiment at her own request and another one was discarded because of her restlessness in the course of the experiment. All students were twenty-one-years old and they reported taking no medication and had no history of neurological, ophthalmological or systemic disease. Their vision was normal or corrected to normal. Written informed consent was obtained from all participants prior to the start of the experiment.

The experimental paradigm, procedures, features of visual stimuli and their relations to preassigned cognitive task were described in detail in our preceding paper ${ }^{16}$.
Therefore, we describe here only the method of data acquisition and the principles of their analysis.

\section{Data acquisition}

The ML870B80 Exercise Physiology System (ADInstruments Pty Ltd.) was used to record concurrently with EEG the cardio-respiratory and metabolic functions of our subjects during their cognitive activity in the course of the whole experiment. The system includes ML870 PowerLab 8/30 data acquisition unit with Chart software that provides control of ADInstruments hardware and includes a variety of analysis features such as XY plotting, differential, integral and spectral calculations. Other parts of the Exercise Physiology System are ML206 Gas Analyser, MLA246 Gas Mixing Chamber, ML141 Spirometer, ML309 Thermistor Pod and MLA240 Exercise Physiology Accessory Kit consisting of Respiratory Flow Head, Hans Rudolph TwoWay Non-Rebreathing Face Mask and other accessories. The Bio Amplifier ML132, Piezo-electric Finger Pulse Transducer MP100, Metabolic Module MLS240, Heart 
Rate Variability Module MLS310 and ECG Analysis Module MLS360 for Chart software are also parts of Exercise Physiology System.

The Gas Analyser measured oxygen $\left(\% \mathrm{O}_{2}\right)$ and carbon dioxide $\left(\% \mathrm{CO}_{2}\right)$ concentrations in expired air sampled from the Gas Mixing Chamber. The Spirometer monitored airflow (1/s), the Thermistor Pod followed the temperature of respired air, the Bio Amplifier amplified finger pulses and the Chart software recorded all of these signals on the hard disk of a computer for later off-line replay and analysis.

\section{Data analysis}

Metabolic Module, Heart Rate Variability Module and ECG Analysis Module for Chart were used for off-line analysis of experimental data. Expired Minute Ventilation $\left(\mathrm{V}_{\mathrm{E}}\right)$, Oxygen Consumption $\left(\mathrm{V}_{\mathrm{O} 2}\right)$, Carbon Dioxide Production $\left(\mathrm{V}_{\mathrm{CO}_{2}}\right)$ and Average Heart Rate (BPM) were ascertained for four periods: (1) rest or starting period, (2) reference period, (3) cognitive task solving period and (4) recovery period. Each period was defined by the type of presented visual stimuli and by the prearranged cognitive activity related to visual stimuli.

In the rest (starting) period no visual stimuli appeared while in the reference period a white blank oval on a dark background emerged on the screen (reference visual stimulus). The presence of reference stimuli did not require any cognitive activity of the subject. However, the presentation of other two visual stimuli (unfolded cube or net of sixteen small squares) exacted either solving of the cognitive task from subject (cognitive task solving period) or solely viewing the visual stimuli without any cognitive activity (recovery period) - the latter activity succeeded after the successful cognitive task solution. The average values of tested parameters were calculated during the recovery period four times, that is, for the first, second, third and fourth 30 -second time intervals.

StatSoft software package (StatSoft, Tulsa, OK) was used for statistic processing of the metabolic and cardiorespiratory data. The score FPI parameters of Freiburg's Personality Inventory ${ }^{12}$ were also considered in the statistic analysis.

\section{RESULTS}

The dynamics of $V_{E}, H R, V_{O 2}$ and $V_{C O 2}$ in the course of the experiment

Fig. 1 summarizes the dynamics of tested parameters in the course of the experiment. From it follows that the momentary functional state of subject's brain (i.e., period of the experiment) determines the average values of all measured parameters. During the cognitive task solving period the Expired Minute Ventilation $\left(\mathrm{V}_{\mathrm{E}}\right)$, Oxygen consumption $\left(\mathrm{V}_{\mathrm{O} 2}\right)$ and Carbon Dioxide Production $\left(\mathrm{V}_{\mathrm{CO} 2}\right)$ reach the lowest average values while the average heart rate (HR) behaves reversely - it is highest in the cognitive task solving period. Furthermore, the average $\mathrm{V}_{\mathrm{E}}, \mathrm{V}_{\mathrm{CO} 2}$ and $H R$ values except $V_{\mathrm{O} 2}$ value differ significantly from the average values of the same variable measured in the rest period.

The considerable decreases of $\mathrm{V}_{\mathrm{E}}, \mathrm{V}_{\mathrm{O} 2}$ and $\mathrm{V}_{\mathrm{CO} 2}$ during the cognitive task solving was replaced by the significant increase of all variables at the beginning of the recovery period - all averages at the first 30-second interval of the recovery period are significantly higher than in the rest period and cognitive task solving periods. HR shows a similar dynamics also but contrary to other tested parameters, HR is lower at the beginning of the recovery period than it was in the period of cognitive task solving.

From Fig. 1 it also follows that changes of all tested variables evoked by mental load during cognitive task solving rapidly disappear during the first minute of the recovery period except $\mathrm{V}_{\mathrm{O} 2}$ - the latter does it only in the third 30-second interval. On the other hand, HR behaves in the recovery period differently - in the third and fourth 30 -second intervals it reaches even significantly lower average values than in the rest period.

\section{Participants' personality traits and $V_{E} H R, V_{O 2}$ and $V_{\mathrm{CO} 2}$ changes in the course of the experiment}

The correlation analysis of our data revealed that tested cardiovascular (HR) and metabolic $\left(\mathrm{V}_{\mathrm{E}}, \mathrm{V}_{\mathrm{O} 2}, \mathrm{~V}_{\mathrm{CO} 2}\right)$ parameters are in relation to some personality traits of the subject. These were especially FPI parameter 3 (depression), FPI5 (sociability), FPI8 (moderation), E (extraversion) and in some cases also parameter $\mathrm{N}$ (emotional lability) that in majority of the experiment's periods affected the magnitude of $\mathrm{V}_{\mathrm{E}}, \mathrm{V}_{\mathrm{O} 2}$ and $\mathrm{V}_{\mathrm{CO} 2}$ increase/decrease against the average value of the same parameter in the rest (starting) period of the experiment (see Table 1). Table 1 also demonstrates that the FPI3 and FPI8 score show a direct relation to the magnitude of increase/decrease of tested variables while the FPI5 and E score show an indirect relation. The $\mathrm{N}$ score correlates negatively only with $\mathrm{V}_{\mathrm{E}}$ and $\mathrm{V}_{\mathrm{CO} 2}$ in the cognitive task solving period. In this context it must be emphasized that $\mathrm{N}$ (emotional lability) represented only one FPI parameter that correlated with metabolic variables in the cognitive task solving period of the experiment.

However, much freer are the relations between subject's personality traits and HR changes. It was shown that the score of only two subject's personality traits (FPI1 - nervousness and FPI8 - moderation) from twelve established correlate positively with the size of increase of HR in two periods of the experiment, i.e. in the task solving period and in the first 30 -second interval of the recovery period. On the other hand, the third of the twelve FPI parameters (extraversion) shows an indirect relation to the HR changes during the task solving period.

\section{DISCUSSION}

The fact that average values of expired minute ventilation $\left(\mathrm{V}_{\mathrm{E}}\right)$, oxygen consumption $\left(\mathrm{V}_{\mathrm{O} 2}\right)$ and carbon dioxide production $\left(\mathrm{V}_{\mathrm{CO} 2}\right)$ were in our subjects markedly lower during the cognitive task solving period than during the rest period is unexpected and in some ways surprising. 
We are surprised because there is a numerous of studies $^{\text {see e.g. } 6,7,10,14,15,17,18,20,22}$ demonstrating unequivocally that energy metabolism in the cerebral tissues is, as in other tissues, closely coupled to its functional activity; the higher the functional activity of the brain is the higher energy supply is required.

Allowing for these facts and information that under normal physiological conditions, the majority of energy required for the ATP generation by mitochondria in the adult brain is supplied almost exclusively via complete oxidative metabolisms in the TCA cycle ${ }^{23}$, the subject's oxygen consumption during their high mental activity related to cognitive task solving ought to be increased. Consistent with this is also the conclusion of Gjedde et al. ${ }^{8}$ that resulted from a detailed analysis of published data describing the responses of brain metabolism to different somatosensory and visual stimuli. The authors note that simple somatosensory and visual stimuli with little information content produce a smaller increase in oxygen consumption than do complex somatosensory stimuli and the motor activity based on a qualitative evaluation of the information content of the stimuli. The arising of complex stimuli is followed by an increase in both blood flow and oxygen consumption, i.e. the complex stimulation is accompanied by a significant increase in the brain oxidative metabolism.

The answer to the question why the respiratory parameters behaved differently in our experiment than we expected is not easy. The closest to the truth will be the assumption that respiratory variables measured by us during the cognitive task solving period predicate about the whole-body metabolic rate of an organism than about the energy metabolism of the brain itself. The changes of the respiratory pattern that we observed during the cognitive task solving periods support this claim. The decrease in respiratory rate and decrease in tidal volumes were typical for each of cognitive task solving periods. The effect of a cognitive task performance (solving a puzzle) on the respiratory pattern was also described by Bell et al. ${ }^{1}$. They showed that performance of a cognitive task decreases the initial phase of exercise hyperpnoea. Therefore it seems that the smaller respiratory work related to the changed respiratory pattern of subjects in the cognitive task solving period could account for the lower oxygen consumption in this phase of the experiment.

Contrary to respiratory variables, the heart rate during cognitive task solving periods behaved according to expectation, i.e. its average values were significantly higher during the cognitive task solving than during the reference period. Several other authors described similar dynamics of the heart rate during mental load too ${ }^{\text {see e.g. 2, 3, 4, 5, } 11}$.

The increased activity of the sympathetic nervous system was probably the main cause of subjects' high heart rate when they solved the cognitive tasks. The correlation analysis of our data (the heart rate increase vs. personality traits) proved this assumption. The size of increase in the heart rate during the cognitive task solving correlated positively with the score of nervousness (FPI1) and frustration (FPI8) while the score of extraversion (E) showed negative correlation. Thus, subjects with personal- ity traits related to higher sympathetic activity showed a strong increase of the heart activity during the cognitive task solving and vice versa. Respiratory variables showed similar dependence - they correlated positively with the score of depressiveness (FPI3) and frustration (FPI8) and negatively with the score of sociability (FPI5) and extraversion.

In conclusion, the presented results show that the actual mental load affects the average values of respiratory $\left(\mathrm{V}_{\mathrm{E}}, \mathrm{V}_{\mathrm{O} 2}\right.$ and $\mathrm{V}_{\mathrm{CO} 2)}$ and cardiovascular (HR) parameters. It appears, however, that changes of respiratory variables predicate about the whole-body metabolic rate of an organism rather than about the energy metabolism of its brain. Contrary to respiratory parameters, the actual heart rate during the solving of cognitive tasks has undoubtedly a tighter relation to brain's energy metabolic rate because it affects the oxygen supply of the brain.

\section{REFERENCES}

1. Bell HJ, Feenstra W, Duffin J. The initial phase of exercise hyperpnoea in humans is depressed during a cognitive task. Exp Physiol 2005; 90:357-65.

2. Berntson GG, Cacioppo JT, Binkley PF, Uchino BN, Quigley KS, Fieldstone A. Autonomic cardiac control. III: Psychological stress and cardiac response in autonomic space as revealed by pharmacological blockades. Psychophysiol 1994; 31:599-608.

3. Blitz PS, Hoogstraten J, Mulder G. Mental load, heart rate and heart rate variability. Psychol Res 1970; 33:277-88.

4. Cacioppo JT, Malarkey WB, Kiecolt-Glaser JK, Uchino BN, Sgoutas-Emch SA, Sheridan JF, Berntson GG, Glaser R. Heterogeneity in neuroendocrine and immune responses to brief psychological stressors as a function of autonomic cardiac activation. Psychosom Med 1995; 57:154-64.

5. Delistraty DA, Greene WA, Carlberg KA, Raver KK. Cardiovascular reactivity in Type A and $\mathrm{B}$ males to mental arithmetic and aerobic exercise at an equivalent oxygen uptake. Psychophysiol 1992; 29:264-71.

6. Fox PT, Raichle ME. Focal physiological uncoupling of cerebral blood flow and oxidative metabolism during somatosensory stimulation in human subjects. Proc Natl Acad Sci USA 1986; 83:114044.

7. Fox PT, Raichle ME, Mintun MA, Dence C. Nonoxidative glucose consumption during focal physiologic neural activity. Science 1988; 241:462-4.

8. Gjedde A, Marrett S, Sakoh M, Vafaee M. Model of oxygen delivery to brain tissue in vivo explains beneficial effect of hypothermia in ischemia. Int Congr Ser 2002; 1235:123-35.

9. Guyton AC, Hall JE. Textbook of Medical Physiology, $11^{\text {th }}$ edition. Philadelphia: Elsevier Saunders, 2006.

10. Hoge RD, Atkinson J, Gill B, Crelier GR, Marrett S, Pike GB. Linear coupling between cerebral blood flow and oxygen consumption in activated human cortex. Proc Natl Acad Sci USA 1999; 96:9403-8.

11. Ishibashi K, Yasukouchi A. Analysis of heart rate variability during mental task with reference to ambient temperature. Appl Human Sci 1999; 18:219-23.

12. Kollarik T, Poliakova E, Ritomsky A. Freiburský osobnostný dotaznik (in Slovak). Bratislava: Psychodiagnostické a didaktické testy, 1984.

13. Magistretti PJ, Pellerin L. The cellular bases of functional brain imaging: Evidence for astrocyte-neuron metabolic coupling. Neuroscientist 1997; 3:361-5.

14. Mintun MA, Lundstrom BN, Snyder AY, Vlassenko AG, Shulman GL, Raichle ME. Blood flow and oxygen delivery to human brain during functional activity: Theoretical modeling and experimental data. Proc Natl Acad Sci USA 2001; 98:6859-64. 
15. Parks RW, Loewenstein DA, Dodrill KL, Barker WW, Yoshii F, Chang JY, Emran A, Apicella A, Sheramata WA, Duara R. Cerebral metabolic effect of verbal fluency test: a PET scan study. Clin Exp Neuropsychol 1988; 10:565-75.

16. Petrek J. Pictorial cognitive task resolution and dynamics of eventrelated potentials. Biomed Pap Med Fac Univ Palacky Olomouc Czech Repub 2008; 152:223-230.

17. Roland PE. Changes in brain blood flow and oxidative metabolism during mental activity. News Physiol Sci 1987; 2:120-4.

18. Roland PE, Eriksson L, Stone-Erlander S, Widen L. Does mental activity change the oxidative metabolism of the brain. J Neurosci 1987; 7:2373-89.

19. Roy CS, Sherrington CS. On the regulation of the blood supply of the brain. J Physiol 1890; 11:85-108.
20. Schuepbach D, Merlo MCG, Goenner F, Staikov I, Mattle HP, Dierks T, Brenner HD. Cerebral hemodynamic response induced by the Tower of Hanoi puzzle and Wisconsin Card Sorting test. Neuropsychologia 2002; 40:39-53.

21. Sokoloff L. Relation between physiological function and energy metabolism in the central nervous system. J Neurochem 1977; 29:13-26.

22. Sokoloff L. Relationships among local functional activity, energy metabolism, and blood flow in the central nervous system. Fed Proc 1981; 40:2311-6.

23. Sokoloff L. Energetics of functional activation in neural tissues. Neurochem Res 1999; 24:321-9. 